\title{
Implantable Collamer Posterior Chamber Intraocular Lenses: A Review of Potential Complications
}

\author{
Paulo Fernandes, PhD; José M. González-Méijome, PhD; David Madrid-Costa, PhD; \\ Teresa Ferrer-Blasco, PhD; Jorge Jorge, PhD; Robert Montés-Micó, PhD
}

\section{ABSTRACT}

PURPOSE: To review the peer-reviewed literature reporting postoperative complications of the most recent models of Visian Implantable Collamer posterior chamber intraocular lenses (ICL, STAAR Surgical Co).

METHODS: A literature search of the PubMed database was performed to identify all articles related to ICL complications. Articles were obtained and reviewed to identify those that reported complications using the latest ICL designs.

RESULTS: Cataract was the major postoperative complication reported: 136 (5.2\%) in 2592 eyes. Of those, $43.4 \%(n=59)$ were reported within 1 year, $15.4 \%$ $(n=21)$ between 1 and 3 years, and $35.3 \%(n=48) \geqslant 3$ years after ICL implantation. Twenty-one (15.4\%) cataracts were reported as surgically induced, 46 (33.8\%) eyes had poor vault $(<200 \mu \mathrm{m})$, and cataract surgery was carried out in $27.9 \%(n=38)$ of eyes. Early acute intraocular pressure increase was also reported to be relatively frequent, whereas acute pupillary block was less frequent and mostly resolved with additional iridotomies. A total of 42 ICLs were explanted due to cataract and IOP. Reported endothelial cell loss varied from $9.9 \%$ at 2 years to $3.7 \% 4$ years postoperatively. This loss was reported to be more pronounced within the first 1 to 2 years, with stability or lower progression after that time.

CONCLUSIONS: The majority of reported complications after ICL implantation are cataract formation. The improvements in lens geometry and more accurate nomograms applied to the selection of the lens to be implanted, in addition to the surgeon's learning curve, might be factors in the decreased occurrence of postoperative complications reported currently. [J Refract Surg. 2011; $x x(x): x x x-x x x$.

doi:10.3928/1081597X-20110617-01

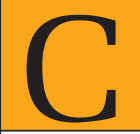

urrently, phakic intraocular lenses (PIOLs) are generally accepted as an alternative treatment for ametropia correction among various refractive ranges, and their implantation is an emerging technique within the field of refractive surgery. Faster visual recovery, high efficacy and stability of visual quality, preservation of accommodation, and reversibility are several advantages that have been attributed to PIOL implantation. ${ }^{1,2}$

The Visian Implantable Collamer Lens (ICL; STAAR Surgical Co, Monrovia, California) is the only posterior PIOL that is currently approved by the United States Food and Drug Administration (FDA) for the treatment of moderate to severe myopia. ${ }^{1}$ It is a foldable PIOL consisting of a plate-haptic design with a central convex/concave optical zone and a forward vault to minimize contact with the crystalline lens. After the first prototypes were implanted several models followed, with major changes occurring in the built-in vault height to warrant consistent clearance from the crystalline lens and have reduced previous problems due to inadequate vaulting. Several published studies have confirmed ICL implantation as a feasible treatment to correct myopia, ${ }^{2-4}$ hyperopia, ${ }^{5-7}$ or astigmatism, ${ }^{8-13}$ with clinical and visual results as good as or better than laser procedures. ${ }^{14-16}$ Patients who are not suitable candidates for corneal reshaping procedures, and in whom optical correction with spectacles or contact lenses is either challenging or renders poor results, ${ }^{9,17-22}$ can benefit from this surgical solution.

From Clinical \& Experimental Optometry Research Lab, Department of Physics (Optometry), School of Sciences. University of Minho, Portugal (Fernandes, González-Méijome, Jorge); and GIO, Optics Department, Faculty of Physics, University of Valencia, Spain (Madrid-Costa, Ferrer-Blasco, Montés-Micó).

This research was supported in part by Ministerio de Ciencia e Innovación Research Grants to Dr Montés-Micó (\#SAF2008-01114-E\# and \#SAF200913342\#) and Fundação para a Ciência e Tecnologia of Portugal through a grant to Dr Fernandes (\#FCT-SFRH-BD-34303-2007\#).

The authors have no proprietary interest in the materials presented herein.

Correspondence: Robert Montés-Micó, PhD, University of Valencia, C/ Dr. Moliner 50, 46100 Valencia, Spain. E-mail: robert.montes@uv.es

Received: September 3, 2010; Accepted: May 27, 2011

Posted online: June 30, 2011 


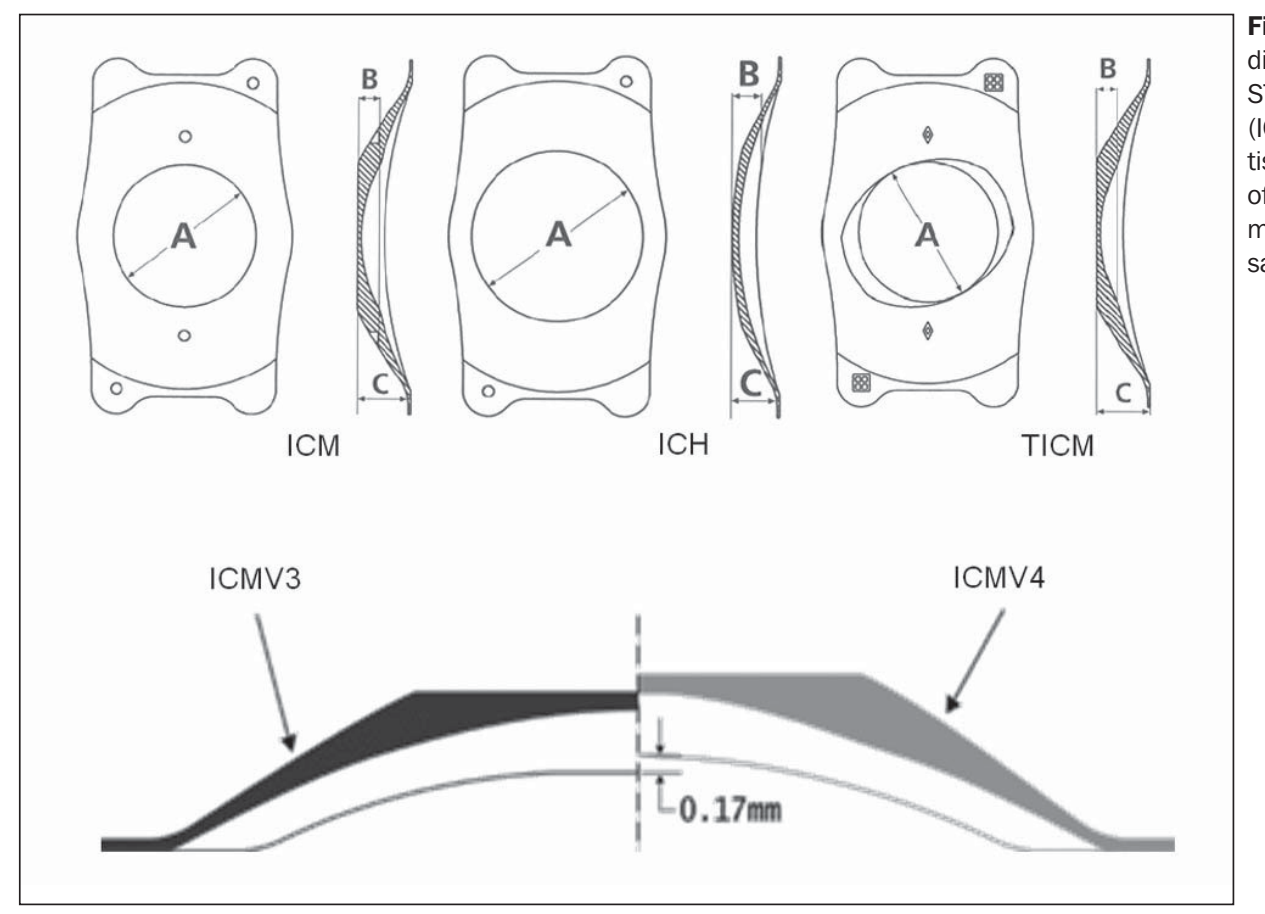

Figure 1. Top) Front and side view of the different Implantable Collamer Lens (ICL; STAAR Surgical Co) models for myopia (ICMV4), hyperopia (ICHV3), and astigmatism (TICMV4). Bottom) Change in vault of the ICMV4 lens compared to the ICMV3 model. Note: The ICHV3 model has the same vault as the ICMV4 model.

Although the published studies reporting results of ICL implantation have low rates of adverse events, carrying out a comparative analysis of the occurrence, type, and visual outcomes of postoperative complications has proven difficult and variable, ${ }^{23}$ as the majority of published studies include different versions of earlier models of ICLs. To provide an updated view of current potential threats of ICL implantation, the present article provides results and conclusions derived from published, peerreviewed studies reporting the outcomes and potential complications of the latest Visian ICL models.

\section{ICL MODELS AND LITERATURE REVIEW}

\section{Clinical Studies Reporting Postoperative COMPLICATIONS AFTER VISIAN ICL IMPLANTATION}

A Medline search from January 1999 to May 2010 was performed to identify all journal articles related to posterior PIOLs. The terms posterior PIOL, Implantable Collamer Lens, Implantable Contact Lens, and ICL were used for a wide and sensitive search. Other searches were performed to identify additional articles that were pertinent to clinical results or ICL complications using terms such as complications of PIOLs, vault, anterior subcapsular cataract, pigment dispersion, intraocular pressure (IOP), endothelial loss, cataract extraction, angle narrowing, endophthalmitis, and retinal detachment.

Copies of the articles were obtained and reviewed to identify those that reported original clinical data or complications after ICL implantation. Furthermore, their reference lists were searched manually for additional articles published in peer-reviewed journals. Only journal articles published in English were included. Only those articles using the latest designs of Visian ICL (V4 for myopia and astigmatism and V3 for hyperopia) were included. Articles reporting complications after ICL implantation in which the exact numbers of eyes being affected were unknown or the ICL model was not reported were excluded. Particular attention was given to avoid duplication of data of published papers covering previously published cases; only those adding new cases were included. Of those papers including different and earlier versions of the Visian ICL, only those cases implanted with the latest version of the lens were included. The significant complications reported regarding safety, such as anterior subcapsular cataract formation, increased IOP, endothelial cell loss, and any other clinical complications represent the outcomes of interest for this review.

\section{VISIAN ICL MODELS}

The Visian ICL is a foldable PIOL made from a biocompatible material named Collamer, composed of a hydrophilic porcine collagen $(<0.1 \%) /$ hydroxyethyl methacrylate copolymer with an ultraviolet-absorbing chromophore. It features a plate-haptic design with a central convex/concave optical zone and incorporates a forward vault to minimize contact of the ICL with the central anterior capsule of crystalline lens. This lens was designed to be placed in the posterior chamber behind the iris with the haptic zone resting on the ciliary sulcus. 
After the first prototypes were implanted, some similar models followed with slight modifications, mainly in the built-in vault height. The latest Visian ICL models are the ICMV4 for myopia, ICHV3 for hyperopia, and TICMV4 for myopic astigmatism. The ICL is a rectangular, 7-mm-wide lens implant, available in four overall lengths $(11.5,12,12.5$, and $13 \mathrm{~mm}$ for the myopic and toric lenses, so called ICM and TICM, respectively; and $11,11.5,12$, and $12.5 \mathrm{~mm}$ for the hyperopic lenses, so called ICH). The optic diameter ranges from 4.65 to $5.5 \mathrm{~mm}$ in the ICM and TICM models, depending on the dioptric power, being always $5.5 \mathrm{~mm}$ for ICH lenses. Front and side views of the Visian ICL V4 for myopia, hyperopia, and astigmatism are shown in Figure 1 (top) along with a comparison between the vault of the Visian V3 and Visian V4 for myopia (see Fig 1, bottom). In an attempt to increase the clearance from the anterior crystalline lens surface, and therefore minimize the risk of iatrogenic subcapsular anterior opacities, the $\mathrm{V} 4$ has an additional 0.13 to $0.21 \mathrm{~mm}$ of anterior vault height due to the steeper radius of curvature of the base curve and dioptric power (see Fig 1). When appropriately selected, the lens creates a clearance space over the whole anterior crystalline lens surface.

\section{LITERATURE REVIEW RESULTS}

An initial literature search identified 108 articles reporting the results of ICL implantation to correct different degrees of myopia, hyperopia, and astigmatism, among other applications. Based on the defined criteria, 44 articles were included in the present review.

Following the criteria previously quoted, and after a careful and systematic review of the complete articles, the postoperative complications and their treatment were obtained. The major postoperative complications documented for these lenses were crystalline lens opacities, increased IOP and pupillary block, and endothelial cell loss. The occurrence of cataract formation was determined as a percentage of the sum of cataract events reported over the total number of ICLs implanted. The percentages of complications given herein are not values of incidence on the general population undergoing these procedures. Instead, these reflect the percentage of cases reported over the whole sample analyzed in the articles surveyed.

\section{Crystalline lens Opacity}

Table 1 shows a summary of studies reporting cataract development after implantation with the latest ICL models. ${ }^{7,10,13,16,24-37}$ Data from 13 articles reporting cataract development after implantation of ICMV4 for myopia, ${ }^{13,25-35} 3$ reports on ICHV3 for hyperopia, $, 25,28$ and 4 reports on TICM for astigmatism ${ }^{10,13,16,37}$ are pre-

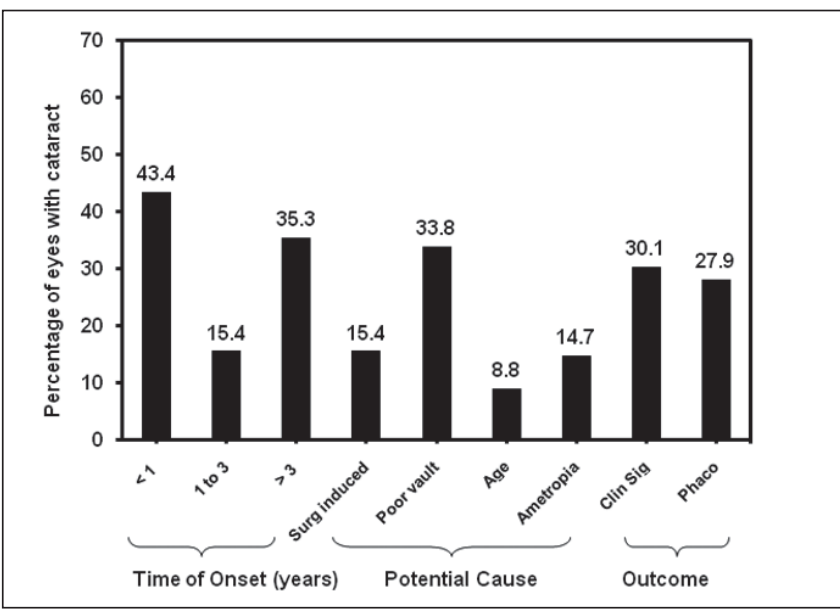

Figure 2. Time of onset (years), potential causes (surgically induced, poor vault, age, and high ametropia), and clinical outcomes (clinically significant cataract and phacoemulsification) of anterior subcapsular cataract after ICL implantation. Clinically insignificant cataracts are not reported.

sented, comprising a total of 2592 eyes surveyed. Of those eyes, $2142(82.6 \%)$ were implanted with the ICMV4, $112(4.3 \%)$ with the ICHV3, and $338(13.0 \%)$ with the TICMV4. A total of 136 (5.2\%) eyes have been reported with cataract, and the occurrence varied within a range from $1.3 \%^{31}$ to $28 \%{ }^{35}$ in the ICM group, $6 \%^{7}$ to $14.3 \%^{28}$ in the ICH group, and $2.3 \%^{16}$ to $10.4 \%^{13}$ in the TICM group. The majority of ICL-associated cataracts were reported as being anterior subcapsular. For those reporting the time of onset, the average time for the development of cataract after ICL implantation varied from $125 \pm 116$ days (range: 1 week to 14 months) ${ }^{22}$ to $44 \pm 31$ months (range: 7 to 120 months). ${ }^{35}$ Of those eyes developing cataract for which the approximate time of onset was known, 43.4\% (n=59) were reported within 1 year, 15.4\% $(\mathrm{n}=21)$ between 1 and 3 years, and $35.3 \%(\mathrm{n}=48) \geqslant 3$ years after ICL implantation (Fig 2). For the remaining eyes $(n=8)$, the time of onset could not be accurately determined.

Early crystalline lens opacities ( $>40 \%$ ) were reported to be possibly related with surgical trauma or ICL-crystalline contact, as they directly involved the anterior capsule as suggested by the authors of the articles surveyed. In the present analysis, 21 (15.4\%) eyes with cataract were reported as surgically induced, mostly associated to inadvertent lens touch during ICL insertion or other intraoperative complications. Lackner et a ${ }^{26}$ reported 4 eyes developing cataract due to a prolonged surgery in elderly patients with a shallow anterior chamber and narrow pupil. Sanders ${ }^{30}$ reported 1 patient developing cataract after vitreoretinal manipulation. SanchezGaleana et $\mathrm{al}^{25}$ observed that most of the early-onset cataracts occurring in the immediate postoperative period 
TABLE 1

\section{Studies Reporting Incidence of Anterior Subcapsular Cataract After Implantable Collamer Lens (ICL) Implantation}

\begin{tabular}{|c|c|c|c|c|}
\hline Study & Lens Type & No. Eyes & Age (Range) (y) & SE (Range) (D) \\
\hline Gonvers et $\mathrm{al}^{24}$ & $\mathrm{ICM}$ & 13 & $39.9 \pm 9(22$ to 50$)$ & $-14.87 \pm 5.89(-6.78$ to -28.25$)$ \\
\hline Sanchez-Galeana et $\mathrm{al}^{25}$ & $\mathrm{ICM}$ & 96 & $37.1 \pm 8.4$ (21 to 60$)$ & - \\
\hline Lackner et $\mathrm{al}^{26}$ & $\mathrm{ICM}$ & 76 & $48.3 \pm 7.4$ (21 to 59$)$ & $-16.5 \pm 5.60(-5.50$ to -33.40$)$ \\
\hline Sarikkola et $a^{27}$ & $\mathrm{ICM}$ & 26 & $34(24$ to 42$)$ & $-15.10 \pm 4.59(-6.75$ to -23.50$)$ \\
\hline Bleckmann \& Keuch ${ }^{28}$ & $\mathrm{ICM}$ & 99 & $42.7 \pm 11.9$ & $8.56 \pm 4.30(-4.00$ to 19.25$)$ \\
\hline Chang \& Meau $^{29}$ & $\mathrm{ICM}$ & 61 & 34.9 & $-14.54 \pm 3.61(-7.00$ to -24.75$)$ \\
\hline Sanders ${ }^{30}$ & $\mathrm{ICM}$ & 526 & $36.5 \pm 5.9$ (22 to 45$)$ & $-10.06 \pm 3.74(-3.00$ to -20.00$)$ \\
\hline Alfonso et $\mathrm{al}^{31}$ & $\mathrm{ICM}$ & 964 & $32.50 \pm 6.05$ (18 to 53 ) & $-9.47 \pm 4.12(-3.25$ to -24.00$)$ \\
\hline Chung et $\mathrm{al}^{32}$ & $\mathrm{ICM}$ & 49 & $34.3 \pm 9.5$ (21 to 49$)$ & $-14.00 \pm 4.00(-6.25$ to -23.25$)$ \\
\hline Kamiya et $\mathrm{al}^{33}$ & $\mathrm{ICM}$ & 56 & $37 \pm 10.3$ (21 to 59$)$ & $-9.83 \pm 3.00(-4.00$ to -15.25$)$ \\
\hline Boxer Wachler et $\mathrm{al}^{34}$ & $\mathrm{ICM}$ & 30 & 39.6 (25 to 56$)$ & $-11.48 \pm 3.84(-7.00$ to -20.25$)$ \\
\hline Lindland et $a^{13}$ & $\mathrm{ICM}$ & 48 & 36 (19 to 52$)$ & $-9.10(-4.30$ to -24.30$)$ \\
\hline Schmidinger et $\mathrm{al}^{35}$ & $\mathrm{ICM}$ & 98 & $36 \pm 10(10$ to 46$)$ & $-16.40 \pm 5.40(-5.50$ to -29.00$)$ \\
\hline Pesando et $\mathrm{al}^{7}$ & $\mathrm{ICH}$ & 50 & $38.41 \pm 4.9$ (31 to 55$)$ & $+5.78 \pm 2.54(+2.50$ to +11.75$)$ \\
\hline Sanchez-Galeana et $\mathrm{al}^{25}$ & $\mathrm{ICH}$ & 34 & - & - \\
\hline Bleckmann \& Keuch ${ }^{28}$ & $\mathrm{ICH}$ & 28 & - & $+3.62 \pm 1.72(+2.75$ to +7.75$)$ \\
\hline Sanders et $\mathrm{al}^{10}$ & TICM & 210 & $36.4 \pm 7.4$ (21 to 45$)$ & $\begin{array}{l}-9.36 \pm 2.66(-2.38 \text { to }-19.50) \\
C Y L 1.93 \pm 0.84(1.00 \text { to } 4.00)\end{array}$ \\
\hline Schallhorn et al ${ }^{16}$ & $\mathrm{TICM}$ & 43 & $30.8 \pm 6$ & $\begin{array}{l}-8.04 \pm 1.28(-6.00 \text { to }-20.00) \\
\text { CYL } 1.73 \pm 0.62(1.00 \text { to } 4.00)\end{array}$ \\
\hline Lindland et al ${ }^{13}$ & $\mathrm{TICM}$ & 29 & 34.6 (25 to 48$)$ & $\begin{array}{l}-8.50(-3.50 \text { to }-17.50) \\
\text { CYL } 2.50(1.00 \text { to } 4.80)\end{array}$ \\
\hline Kamiya et $\mathrm{al}^{37}$ & $\mathrm{TICM}$ & 56 & 35.5 (23 to 50$)$ & $\begin{array}{l}-10.37 \pm 2.78(-4.00 \text { to }-17.25) \\
\text { CYL } 2.15(0.75 \text { to } 4.00)\end{array}$ \\
\hline Total & & 2592 & & \\
\hline
\end{tabular}

(up to 3 months) were frequently asymptomatic and associated with surgical trauma. Surgeon learning curve has also been reported by those authors as a risk factor for the early development of cataract. ${ }^{25}$ This has been supported by their findings, in which $79 \%$ (11/14) of opacities occurred in the first or second implantation of surgeons-in-training, and with increased surgical experience the incidence of opacities dropped from $19 \%$ to $0 \%$ for the same surgeon. ${ }^{25}$ Sanders et al, ${ }^{38}$ in a multicenter trial, found that the incidence of lens opacities increased with inexperienced surgeons and 2 of 19 surgeons in their study were responsible for the majority of observed lens opacities.

Regarding cataract development 1 year after ICL implantation, several factors have been reported. Patient-dependent factors at the time of ICL implantation, such as age and preoperative refractive status, were considered predictive risk factors for cataract development after ICL implantation by several studies. Gonvers et $\mathrm{al}^{39}$ reported higher incidence of cataract development in older patients $14 \%$ of young patients [age: 10 to 40 years] versus $37 \%$ of older patients [age: 41 to 50 years]). Lackner et $\mathrm{al}^{26}$ reported in a series of 76 eyes that all eyes with late cataract development $(n=11)$ were in patients older than 50 years. In a study by Alfonso et al, ${ }^{31}$ in $1.3 \%$ of eyes (13/964) developing cataract after ICL implantation, patient age was the parameter with the highest correlation with cata- 


\begin{tabular}{|c|c|c|c|c|c|}
\hline \multirow[b]{2}{*}{ Follow-up (Range) (mo) } & \multirow[b]{2}{*}{ Total ASC (\%) } & \multicolumn{3}{|c|}{ Onset (No. Eyes [\%]) } & \multirow[b]{2}{*}{ Potential Etiology } \\
\hline & & Early $(<\mathbf{1} \mathbf{y})$ & 1 to $3 y$ & Late $(>3 y)$ & \\
\hline $7.4 \pm 2.8$ (3 to 14$)$ & $1(7.7)$ & $1 / 13$ & - & - & Low vault \\
\hline $12.2 \pm 4.9$ (8 to 27$)$ & $6(6.3)$ & $6 / 96$ & - & - & Surgically induced \\
\hline $24 \pm 11.5$ & $11(14.5)$ & $9 / 69$ & $1 / 42$ & $1 / 19$ & Age \\
\hline 13 & $2(7.7)$ & $2 / 26$ & - & - & Surgically induced \\
\hline $31 \pm 18$ & $5(5.1)$ & - & - & - & - \\
\hline $13.67 \pm 8.51$ (1 to 32 ) & $1(1.6)$ & - & $1 / 17$ & - & Surgically induced \\
\hline 60 & $31(5.9)$ & $18 / 428$ & $5 / 468$ & $8 / 384$ & High myopia; age \\
\hline 36 & $13(1.3)$ & $2 / 506$ & $7 / 147$ & $4 / 139$ & $\begin{array}{l}\text { High myopia; age; } \\
\text { low vault }\end{array}$ \\
\hline $33.2 \pm 7.3$ (24 to 47$)$ & $2(4.1)$ & $2 / 48$ & - & - & Surgical trauma; low vault \\
\hline 48 & $8(14.3)$ & $2 / 56$ & $6 / 56$ & - & Surgical trauma; low vault \\
\hline 3 & $2(6.7)$ & $2 / 30$ & - & - & Surgical trauma; low vault \\
\hline 65 (11 to 84) & 7 (14.6) & $1 / 48$ & - & $6 / 48$ & $\begin{array}{l}\text { ICL-crystalline contact; } \\
\text { low vault }\end{array}$ \\
\hline $74.1 \pm 23.1$ (26 to 124$)$ & $23(28.0)$ & - & - & $23 / 84$ & Low vault \\
\hline 46 (6 to 120$)$ & $3(6.0)$ & - & - & $3 / 6$ & Low vault \\
\hline 12 & $4(11.7)$ & $4 / 34$ & - & - & $\mathrm{ICH}$ size $11 \mathrm{~mm}$ \\
\hline $31 \pm 18$ & $4(14.3)$ & - & - & - & Low vault \\
\hline 12 & $6(2.9)$ & $6 / 200$ & - & - & - \\
\hline 12 & $2(2.3)$ & $1 / 43$ & $1 / 43$ & - & Low vault \\
\hline 60 (10 to 76$)$ & $3(10.4)$ & - & - & $3 / 29$ & $\begin{array}{l}\text { ICL-crystalline contact; } \\
\text { low vault }\end{array}$ \\
\hline \multirow[t]{2}{*}{12} & $3(5.4)$ & $3 / 56$ & - & - & - \\
\hline & $136(5.2)$ & $58 / 1715$ & $21 / 773$ & $48 / 765$ & \\
\hline
\end{tabular}

ract development; additionally, those eyes tended to present lower vault values, average lower ICL size, and shallower anterior chamber depth. In a study by Sanders, ${ }^{30}$ all clinically significant cataracts occurred in the group with myopia $>-10.00$ diopters (D). In the study by Sanchez-Galeana et al, ${ }^{25}$ mean spherical equivalent refraction in eyes with cataract was $-19.20 \pm 5.40 \mathrm{D}$ versus $-17.10 \pm 4.70 \mathrm{D}$ for those without cataract development in the myopic group and $+8.60 \pm 1.20 \mathrm{D}$ versus $+6.20 \pm 1.90 \mathrm{D}$ for those with and without cataract development in the hyperopic group. Furthermore, all 4 opacities in the hyperopic group occurred in eyes with a lens diameter of $11.0 \mathrm{~mm}$, which is no longer produced by the manufacturer.
The separation between the ICL and crystalline lens is also an important issue associated with cataract formation after ICL implantation. It has been suggested that insufficient vault might induce cataract formation by mechanical interaction or trauma on the anterior capsule. ${ }^{39}$ Additionally, poor vault could also lead to disturbances in aqueous flow, interfering with lens nutrition and causing metabolic disturbances to the crystalline lens. ${ }^{1,40,41}$ In those reports in which data were available regarding vault values, ${ }^{7,13,16,24,28,31-34} 46$ (33.8\%) eyes were documented to have poor vault $(<200 \mu \mathrm{m})$. An underestimation in the selection of the ICL diameter was frequently associated with poor vault immediately after surgery and, in these cases, anterior subcapsular cataract was more likely to 
occur due to ICL-crystalline lens contact.

In the study by Gonvers et al, ${ }^{24}$ the one cataract observed with the V4 model was associated with absence of vault (direct contact between ICL and crystalline lens). In a study conducted in myopic Asian eyes by Chang and Meau, ${ }^{29}$ the only cataract occurred in a case in which the lens was considered too small. Sarikkola et $\mathrm{al}^{27}$ reported that the appearance of cataract could first be seen beneath the thickest part in the midperiphery of the ICL as a circle on the anterior crystalline lens surface in myopic eyes and in the central area in hyperopic eyes. This characteristic location of the cataract might be expected to affect patients with higher refractive errors due to the inherent geometry of the lenses. Moreover, a trend for vault to slightly decrease over time has been reported, which could lead to similar problems even if enough vault was warranted immediately after surgery. ${ }^{31}$ Schmidinger et $\mathrm{al}^{35}$ reported a significant and continuous reduction in central vaulting over a 10-year period in eyes treated with an ICMV4 model-eyes that developed cataract with this lens had midperipheral contact between the ICL and anterior crystalline lens surface. They also reported a mean vaulting of $216 \pm 104 \mu \mathrm{m}$ at the initial manifestation of cataract and $98 \pm 100 \mu \mathrm{m}$ by the time of cataract removal. In the study by Boxer Wachler et al, ${ }^{34}$ of the two eyes that had trace cataract, one eye had no vault and the ICL was replaced by a larger diameter lens.

Studies that evaluated the pathophysiology of anterior subcapsular cataracts secondary to ICL confirm those associations between cataract development and lower vault. ${ }^{28,42,43}$ In a study of 127 eyes by Bleckmann and Keuch, ${ }^{28} 5$ eyes that had vault $<150 \mu \mathrm{m}$ developed cataract. Histological examination of anterior capsule fragments after phacoemulsification revealed some evidence that contact or closeness of the phakic lens to the crystalline capsule might have induced permeation disturbances, which may have led to a cascade of metabolic disturbances and transformations within the epithelial cells. Using light microscopy, Khalifa et al ${ }^{42}$ evaluated the histopathology of anterior subcapsular cataract associated with ICL in 4 eyes that had ICL explantation due to low vault and cataract surgery. The histopathology of the anterior subcapsular cataract showed fibrous metaplasia of the anterior subcapsular lens epithelial cells with dense fibrous tissue attached to the inner surface of the anterior capsulorrhexis specimens corresponding to the areas of anterior subcapsular cataract. In addition, light microscopy of the explanted ICL showed a varied amount of pigment deposition and locations, and the authors state that these histopathologic changes are thought to be due to disturbance of the aqueous flow, causing metabolic changes within the crystalline lens structure or intermittent microtrauma. ${ }^{42}$

Regarding clinical significance of cataract, most were reported as nonprogressive or slowly progressive and asymptomatic and were placed under surveillance. However, in $30.1 \%(n=41)$ of eyes, the opacity became clinically significant and cataract surgery was performed in $27.9 \% \quad(n=38)$ of eyes. The duration of follow-up should also be taken into account given that the occurrence of cataract is higher in patients with longer follow-up. ${ }^{26,33,35}$

Combined PIOL explantation and cataract surgery was reported to be an easy and feasible procedure ${ }^{43}$ once the lens was extracted through its original corneal incision or at a site identical to the original incision with usually minimal trauma because of the lens' flexibility. ${ }^{44,45}$ All patients in studies published to date who underwent combined PIOL explantation and phacoemulsification had successful reimplantation of pseudophakic IOLs and did not show any adverse effects derived from the combined procedure. Bleckmann and Keuch $^{28}$ reported an improvement in corrected distance visual acuity (CDVA) after cataract surgery of $1.44 \pm 1.33$ lines more than that before ICL implantation. Morales et $\mathrm{al}^{46}$ also reported that the mean CDVA before ICL implantation, after ICL implantation, and after cataract surgery was $0.31 \pm 0.32,0.28 \pm 0.19$, and $0.27 \pm 0.21 \log M A R$, respectively. Kamiya et $\mathrm{al}^{45}$ reported an improvement of one line in CDVA in the only ICL V4-induced cataract observed in the study. In the study by Khalifa et al, ${ }^{42}$ the four eyes that underwent ICL explantation and cataract surgery achieved CDVA of $20 / 20$. With regard to the predictability of these combined procedures, it has been reported that they offer high predictability of the intended correction. Bleckmann and Keuch ${ }^{28}$ stated that refractive error did not exceed 1.00 D irrespective of the initial refraction or degree of hyperopia or myopia. Morales et $\mathrm{al}^{46}$ reported that the percentage of eyes within $\pm 1.00 \mathrm{D}$ of the targeted correction was $71.4 \%$. Kamiya et $\mathrm{al}^{45}$ reported that the percentages of eyes within $\pm 0.50 \mathrm{D}$ and $\pm 1.00 \mathrm{D}$ of the targeted correction 3 months after surgery were $80 \%$ and $90 \%$, respectively. In addition, they also reported a high patient satisfaction rate with visual outcomes with the combined surgery.

It is known that the presence of an IOL will affect axial length measurements. Recently, however, Sanders et $\mathrm{al}^{47}$ determined that the axial length measurements made by partial coherence laser interferometry are not significantly affected by the presence of a phakic ICL. The maximum difference between pre- and postoperative PIOL axial length measurements was less than 0.1 $\mathrm{mm}$, which will barely induce clinically significant errors near $0.25 \mathrm{D}$; even with axial lengths of $30 \mathrm{~mm}$. 
Morales et $\mathrm{al}^{46}$ also stated that the difference between the axial length measurements before ICL implantation and those after was small. These findings may somewhat account for the higher predictability of these combined procedures.

\section{INTRAOCULAR PRESSURE}

Table 2 summarizes those studies reporting an increase in $\mathrm{IOP}^{2,11,26,29,31,32,36,48-57}$ after implantation of the ICL V4 model and the procedures adopted to resolve it. An early rise in IOP was reported to be relatively frequent and usually moderate $(<30 \mathrm{mmHg})$. Incomplete removal of viscoelastic material and instillation of steroid eye drops ${ }^{11,29,32}$ or the reduction of the angle opening distance $(41.5 \%)$ and reduction of the trabecular-iris angle $(31.8 \%)^{32}$ were associated with this rise, which was usually observed within the first month after surgery. When asymptomatic and not followed by marked chamber shallowing, these situations often resolved spontaneously within the first 48 hours and did not need any special treatment or resolved with temporary topical antiglaucoma medication. ${ }^{26,32}$ Chronic pigment dispersion was also suggested as another potential cause of increased IOP ${ }^{58}$ and can be related to preoperative laser iridotomies or chronic iris chafing by the ICL. Chung et $\mathrm{al}^{32}$ found that the mean trabecular meshwork pigmentation at 1 month postoperatively was not significantly different from the preoperative value with the ICL V4 model, and the ongoing reduction observed during postoperative follow-up may reflect the progressive clearing of the pigment dispersion secondary to laser iridotomies. Sanchez-Galeana et $\mathrm{al}^{52}$ reported a patient who developed pigment glaucoma with refractory increase in IOP; medical therapy and lens explantation trabeculectomy were performed to reduce IOP. Chung et $\mathrm{al}^{32}$ reported one eye showing increased IOP with significantly increased trabecular pigmentation 1 week postoperatively, despite low ICL vaulting. Significant pigment deposits were observed on the ICL surface and prolonged antiglaucoma medication was necessary.

In some cases, the rise in IOP remained persistent and a secondary emergency procedure was required. Acute pupillary block ${ }^{2,29,49,51}$ and subsequent narrowing of the iridocorneal angle are considered primary causes of sustained elevated IOP, frequently associated with inadequate preoperative iridotomies ${ }^{2,49,51}$ and/or excessive ICL vault (usually by an overestimation of the ICL $\operatorname{size}^{31,36}$ ). Smallman et $\mathrm{al}^{49}$ reported bilateral ICL explantation because of the risk for further episodes of pupillary block in a patient with delayed pupillary block glaucoma from closure of iridotomies. A similar complication was reported by Park et al. ${ }^{53}$ The majority of cases with pupillary block are success- fully managed by enlargement of existing iridotomies or by the creation of additional surgical peripheral iridectomies, ${ }^{54,55}$ avoiding the need to explant the ICL.

The use of cycloplegic agents was also reported to temporarily relieve IOP in this ICL-induced angle closure mechanism ${ }^{51,56}$ by reducing the inward compressive force on the ICL footplates and consequential ICL vault reduction and avoidance of angle closure. Nevertheless, in some cases, acute angle closure is secondary to nonpupillary block mechanism, ${ }^{50,56,57}$ as described by Khalifa et al. ${ }^{57}$ This nonpupillary block mechanism is mainly due to an overestimation of ICL size and excessively vaulted ICLs, as a result of a poor correlation between white-towhite distance and sulcus-to-sulcus diameter ${ }^{50,57}$ and/or to an abnormally large and irregular ciliary process. ${ }^{56}$ These particular cases do not respond to additional laser or surgical iridotomies and ICL extraction is necessary.

\section{Endothelial Cell Loss}

Table 3 presents a summary of studies reporting endothelial cell loss secondary to implantation of the latest versions of ICL. 7,11,26,32,33,37,59-61 Some discrepancies are present within the data. Some authors reported that mean endothelial cell density was significantly lower at 1 month after ICL implantation by $9.9 \%,{ }^{32}$ and this decrease was maintained during the subsequent 2 years. Pesando et $\mathrm{al}^{7}$ reported $4.7 \%$ cell loss at approximately 6 months, which remained unchanged throughout 10-year follow-up, whereas others reported $6.1 \%$ cell loss after 3 years ${ }^{59}$ and $3.7 \%$ cell loss 4 years after ICL implantation. ${ }^{33}$ Alfonso et al ${ }^{19}$ reported corneal endothelial cell loss of $8.1 \% 2$ years after toric ICL implantation in eyes after penetrating keratoplasty.

Coefficient of variation of endothelial cell size did not show a significant change during the first year after surgery, but it was significantly lower thereafter, ${ }^{32,61}$ whereas mean percentage of hexagonality remained stable or slightly increased throughout the postoperative period. Despite this, in all studies, the rate of endothelial cell loss slowed down substantially from 1 to 2 years, and tended to remain stable or have lower progression after that period. Edelhauser et al ${ }^{61}$ reported a cumulative endothelial cell loss of $8.4 \%$ and $8.5 \%$ over the first 3 and 4 years, respectively. This loss continued at a rate of $2 \%$ to $3 \%$ per year over the first 3 years and a cell increase of $0.1 \%$ between 3 and 4 years of follow-up. From these findings in cell loss behavior, the authors considered prolonged corneal remodeling following the surgical procedure to be the cause of the early corneal endothelial cell loss ${ }^{61}$ whereas further decrease in cell density in the late postoperative period may be due to natural cell loss. ${ }^{62}$

\section{ENDOPHTHALMITIS AND RETINAL DETACHMENT}


TABLE 2

Studies Reporting an Increase in Intraocular Pressure After Implantable Collamer Lens (ICL) Implantation

\begin{tabular}{|c|c|c|c|c|}
\hline Study & No. of Eyes & No. (\%) & Potential Cause & Management \\
\hline Alfonso et $\mathrm{al}^{31}$ & 964 & $12(1.2)$ & High vault & $\begin{array}{l}\text { Temporary topical } \\
\text { medication }\end{array}$ \\
\hline Chun et $\mathrm{al}^{48}$ & 81 & $9(11.1)$ & Steroid & $\begin{array}{l}\text { Temporary topical } \\
\text { medication }\end{array}$ \\
\hline Chang \& Lau ${ }^{11}$ & 44 & $1(2.3)$ & Steroid & $\begin{array}{l}\text { Temporary topical } \\
\text { medication }\end{array}$ \\
\hline Lackner et al ${ }^{26}$ & 76 & $1(1.3)$ & - & $\begin{array}{l}\text { Temporary topical } \\
\text { medication }\end{array}$ \\
\hline Rayner et al ${ }^{36}$ & 126 & $1(0.8)$ & High vault & ICL replacement \\
\hline Chang \& Meau $^{29}$ & 61 & $16(26.2)$ & $\begin{array}{l}\text { Suspected pupillary block } \\
\text { (1 eye), steroid ( } 1 \text { eye) }\end{array}$ & $\begin{array}{l}\text { Temporary topical } \\
\text { medication }\end{array}$ \\
\hline Chung et $\mathrm{al}^{32}$ & 49 & $18(2.0)$ & Pigment dispersion & $\begin{array}{l}\text { Prolonged topical } \\
\text { medication (1 eye) }\end{array}$ \\
\hline Sanders et $\mathrm{al}^{2}$ & 526 & $21(4.0)$ & Pupillary block & Additional iridotomies \\
\hline Smallman et $\mathrm{al}^{49}$ & Case report & 1 & Pupillary block & Additional iridotomies \\
\hline Vetter et $a^{50}$ & Case report & 1 & Pupillary block & ICL explantation \\
\hline Bylsma et al ${ }^{51}$ & Case report & 1 & Pupillary block & Additional iridotomies \\
\hline Sánchez- Galeana et al ${ }^{52}$ & Case report & 1 & Pigment dispersion & ICL explantation \\
\hline Park et $\mathrm{al}^{53}$ & Case report & 2 & Pigment dispersion & ICL explantation \\
\hline
\end{tabular}

Implantation of a posterior chamber PIOL carries a potential risk for intraocular complications such as endophthalmitis and retinal detachment. Allan et al ${ }^{63}$ conducted an anonymous online survey of 234 surgeons in 21 countries to determine how many of their ICL cases had been complicated by endophthalmitis between January 1998 and December 2006. During the study period, 95 (40\%) surgeons responded to the survey with a total of 17954 ICLs implanted and 3 surgeons reported 1 case of endophthalmitis each, a rate of $0.0167 \%$ or approximately 1 case of endophthalmitis per 6000 ICL implantations. Davis et al ${ }^{64}$ reported a case of culture-positive bacterial endophthalmitis 4 days following ICL implantation. The patient made a full visual recovery after proper treatment.

Most ICL implantations are performed in patients with high myopia and long axial length; therefore, these eyes have a predisposition for retinal detachment. ${ }^{2,29,65}$ In the US FDA trial, ${ }^{2} 3$ retinal detachments were reported in 526 eyes. Retinal detachment was reported in 1 eye 15 months after ICL implantation in a study comprising 61 eyes, and this case was attributed to the pre-existing axial length of $31.0 \mathrm{~mm} .^{29} \mathrm{In}$ a retrospective study of 628 eyes implanted with the ICL V4, Martinez-Castillo et al ${ }^{65}$ reported retinal detachment in 11 eyes, which occurred from 1 to 70 months after lens surgery. The authors attributed these cases to preexisting high myopia and long axial length (>30 mm).

\section{DISCUSSION}

Apart from the rare adverse risks of intraocular surgery, mild endothelial cell loss, increased IOP and pupillary block, and cataract formation are the most documented safety concerns related to ICL implantation. Although a number of articles in the peer-reviewed literature support the relatively low rate of complications after ICL implantation, development of anterior subcapsular opacities and clinically significant cataract remain a major concern. In a recent meta-analysis by Chen et al, ${ }^{23}$ the incidence of cataract formation in the STAAR Collamer group (1933 eyes) was 8.48\%. Early cataract formation was attributed to surgical trauma whereas late cataract formation was attributed to ICLcrystalline lens contact. However, the meta-analysis considered all ICL designs, including earlier versions that are now discontinued. In the present literature review comprising 2592 eyes, the occurrence of cataract formation with the latest ICL models was $5.2 \%$. In the US trial, ${ }^{38}$ the rate of symptomatic and asymptomatic anterior subcapsular opacities was $12.6 \%$ with the V3 model and $2.9 \%$ with the V4 model. Furthermore, the rate of clinically significant cataract was $9.2 \%$ in the 


\section{Studies Reporting the Percentage of Endothelial Cell Loss After Implantable Collamer Lens (ICL) Implantation}

\begin{tabular}{|c|c|c|c|}
\hline Study & No. of Eyes & ICL Type (\%) & Endothelial Cell Loss (\%) (Time) \\
\hline Pesando et $\mathrm{al}^{7}$ & 50 & $\mathrm{ICH}$ & $4.7(10 y)$ \\
\hline Kamiya et al ${ }^{33}$ & 56 & ICM & 2.0 (1 y); 3.7 (5 y) \\
\hline Chung et al ${ }^{32}$ & 49 & ICM & $9.9(2 y)$ \\
\hline Lackner et $\mathrm{al}^{26}$ & 76 & ICM & $8.3(1 \mathrm{y}) ; 6.4(3 \mathrm{y})$ \\
\hline Pineda-Fernández et al ${ }^{59}$ & 12 & ICM & $4.9(1 \mathrm{y}) ; 6.1(3 \mathrm{y})$ \\
\hline Dejaco-Ruhswurm et al ${ }^{60}$ & 8 & ICM & $5.5(1 \mathrm{y}) ; 12.3$ (4 y) \\
\hline Edelhauser et al ${ }^{61}$ & 212 & ICM & $8.9(1 \mathrm{y}) ; 9.5$ (4 y) \\
\hline Chang \& Lau ${ }^{11}$ & 44 & TICL & $11.0(1 \mathrm{y})$ \\
\hline Kamiya et al ${ }^{37}$ & 56 & TICL & 2.9 (1 y) \\
\hline Total & 551 & & $7.17 ; 7.51$ \\
\hline
\end{tabular}

V3 group and $0.8 \%$ in the V4 group. These results have also been confirmed by other authors, ${ }^{26,59}$ which support the lower occurrence derived from this review compared to the earlier review by Chen et al. ${ }^{23}$

Overall, the occurrence of early onset cataract seems to have decreased in recent years, which may be attributed to the changes in lens design of the V4 model, compared to the less vaulted anterior models, and surgical-related factors such as the surgeon's learning curve and skill. Despite this refinement in lens design, the selection of lens parameters and the execution of surgical maneuvers are still critical for long-term success as they define the physical position of the lens in the posterior chamber. An underestimation in the selection of the ICL diameter is frequently associated with poor vault $(<250 \mu \mathrm{m})$, thereby increasing the risk of cataract formation, whereas an oversized ICL may result in excessive vault $(>750 \mu \mathrm{m})$, thereby increasing the risk of angle-closure, pupillary block glaucoma, or pigment dispersion glaucoma.

Because the haptics of the ICL rest in the ciliary sulcus, the overall size of the ICL depends on the ciliary sulcus diameter. The ideal approach to selecting the appropriate size ICL would be to directly measure the sulcus-to-sulcus length. Before the development of high-resolution ultrasound biomicroscopy, no system allowed determination of the internal diameter of the ciliary sulcus. This evaluation relied on white-to-white measurement. The ICL's diameter is oversized 0.5 to $1.0 \mathrm{~mm}$ from the white-to-white measurement in myopic eyes, and is the same length or oversized $0.5 \mathrm{~mm}$ in hyperopic eyes, and the amount of ideal postoperative vault must create a clearance space over the whole an- terior crystalline lens surface and was recommended to be equal to 1.0 to 1.5 times the central corneal thicknesses on slit-lamp examination, which corresponds to an approximate value between 400 and $600 \mu \mathrm{m} .{ }^{66}$ However, regardless of the accuracy of the white-towhite measurement, recent studies demonstrate that there is no accurate anatomical relationship between external measurements and internal dimensions. ${ }^{67-69}$ Therefore, white-to-white distance alone may not predict angle or sulcus size, and size mismatches can occur, making this method unlikely to predict accurate vault values. ${ }^{70}$ Moreover, it has been reported that ICL length determined by high-resolution ultrasound biomicroscopy rendered significantly more ideal ICL vault than the conventional white-to-white method. ${ }^{71}$ In addition, changes made in size nomogram also proved to provide a more satisfactory vault. ${ }^{29}$

Other non-surgeon-dependent factors, such as high myopia and consequently higher ICL power, have also been related to earlier cataract development; the potential role of the thicker periphery in high-power lenses has been associated as well.

The anterior segment (including anterior and posterior chambers) is a dynamic rather than static space. Factors such as accommodation and aging or dynamic interactions between the ICL and crystalline lens and with the back surface of the iris during accommodation or pupillary dynamics ${ }^{13,72,73}$ affect the space available between the posterior cornea and anterior crystalline lens surface. Considering the relatively early patient age for the implantation of these lenses, PIOLs such as the ICL are subjected to these variations. Yan et al ${ }^{67}$ have shown that the crystalline lens rises on average 
$28 \mu \mathrm{m}$ per diopter of accommodation, which is associated to a decrease in anterior chamber depth of $24 \mu \mathrm{m}$ per diopter. As the eye ages, accommodation plays a less significant role, but other changes occurring in the crystalline lens that might compromise the amount of safe space from the ICL must be considered. Indeed, it is well known that the anterior chamber decreases in the aging eye. ${ }^{74}$ Such decrease in anterior chamber depth is likely to be induced by the thickening of the aging crystalline lens at an average rate of $24 \mu \mathrm{m} /$ year as reported by Atchison et al. ${ }^{75}$ This might help counterbalance the slight decrease in vault several years after surgery. ${ }^{31,35,76,77}$ Finally, the anatomic configuration and age-related changes of the ciliary muscle must be taken into account. ${ }^{78}$ The age-related increase in anteroposterior thickness of the ciliary muscle in phakic patients $^{54}$ might somewhat affect the positioning of the ICL over time. Recent information about the biometry of the anterior segment of the eye and its changes with age and accommodation should help improve these outcomes even further. Overall, the improvement of new anterior segment imaging should improve the ICL selection nomogram, thus increasing the safety of the procedure. Although ICL implantation can be considered a safe and effective method for the surgical correction of moderate to high refractive errors, follow-up studies are needed to establish the long-term safety of these posterior PIOLs.

\section{AUTHOR CONTRIBUTIONS}

Study concept and design (P.F., J.M.G.M., D.M.C., T.F.B., J.J., R.M.M.); data collection (P.F., J.M.G.M., D.M.C., T.F.B., J.J., R.M.M.); analysis and interpretation of data (P.F., J.M.G.M., D.M.C., T.F.B., J.J., R.M.M.); drafting of the manuscript (P.F., J.M.G.M., T.F.B., R.M.M.); critical revision of the manuscript (D.M.C., J.J.); statistical expertise (J.J., R.M.M.); supervision (R.M.M.)

\section{REFERENCES}

1. Lovisolo CF, Reinstein DZ. Phakic intraocular lenses. Surv Ophthalmol. 2005;50(6):549-587.

2. Sanders DR, Doney K, Poco M. United States Food and Drug Administration clinical trial of the Implantable Collamer Lens (ICL) for moderate to high myopia: three-year follow-up. Ophthalmology. 2004;111(9):1683-1692.

3. Arne JL, Lesueur LC. Phakic posterior chamber lenses for high myopia: functional and anatomical outcomes. J Cataract Refract Surg. 2000;26(3):369-374.

4. Lackner B, Pieh S, Schmidinger G, et al. Outcome after treatment of ametropia with implantable contact lenses. Ophthalmology. 2003;110(11):2153-2161.

5. Bloomenstein MR, Dulaney DD, Barnet RW, Perkins SA. Posterior chamber phakic intraocular lens for moderate myopia and hyperopia. Optometry. 2002;73(7):435-446.

6. Davidorf JM, Zaldivar R, Oscherow S. Posterior chamber phakic intraocular lens for hyperopia of +4 to +11 diopters. J Refract Surg.
1998;14(3):306-311.

7. Pesando PM, Ghiringhello MP, Di Meglio G, Fanton G. Posterior chamber phakic intraocular lens (ICL) for hyperopia: tenyear follow-up. J Cataract Refract Surg. 2007;33(9):1579-1584.

8. Alfonso JF, Fernandez-Vega L, Fernandes P, González-Méijome JM, Montés-Micó. Collagen copolymer toric posterior chamber phakic intraocular lens for myopic astigmatism: one-year follow-up. J Cataract Refract Surg. 2010;36(4):568-576.

9. Alfonso JF, Baamonde B, Madrid-Costa D, Fernandes JP, Jorge J, Montés-Micó. Collagen copolymer toric posterior chamber phakic intraocular lenses to correct high myopic astigmatism. J Cataract Refract Surg. 2010;36(8):1349-1357.

10. Sanders DR, Schneider D, Martin R, et al. Toric Implantable Collamer Lens for moderate to high myopic astigmatism. Ophthalmology. 2007;114(1):54-61.

11. Chang J, Lau S. Toric Implantable Collamer Lens for high myopic astigmatic Asian eyes. Ophthalmology. 2009;116(12):23402347.

12. Elies D, Alonso T, Puig J, Gris O, Güell JL, Coret A. Visian toric implantable collamer lens for correction of compound myopic astigmatism. J Refract Surg. 2010;26(4):251-258.

13. Lindland A, Heger H, Kugelberg M, Zetterstrom C. Vaulting of myopic and toric Implantable Collamer Lenses during accommodation measured with Visante optical coherence tomography. Ophthalmology. 2010;117(6):1245-1250.

14. Sanders D, Vukich JA. Comparison of implantable collamer lens (ICL) and laser-assisted in situ keratomileusis (LASIK) for low myopia. Cornea. 2006;25(10):1139-1146.

15. Kamiya K, Shimizu K, Igarashi A, Komatsu M. Comparison of Collamer toric implantable [corrected] contact lens implantation and wavefront-guided laser in situ keratomileusis for high myopic astigmatism. J Cataract Refract Surg. 2008;34(10):16871693. Erratum in J Cataract Refract Surg. 2008;34(12):2011.

16. Schallhorn S, Tanzer D, Sanders DR, Sanders ML. Randomized prospective comparison of visian toric implantable collamer lens and conventional photorefractive keratectomy for moderate to high myopic astigmatism. J Refract Surg. 2007;23(9):853-867.

17. Lesueur LC, Arne JL. Phakic posterior chamber lens implantation in children with high myopia. J Cataract Refract Surg. 1999;25(12):1571-1575.

18. Alfonso JF, Palacios A, Montés-Micó R. Myopic phakic STAAR collamer posterior chamber intraocular lenses for keratoconus. J Refract Surg. 2008;24(9):867-874.

19. Alfonso JF, Lisa C, Abdelhamid A, Montés-Micó R, Poo-Lopéz A, Ferrer-Blasco T. Posterior chamber phakic intraocular lenses after penetrating keratoplasty. J Cataract Refract Surg. 2009;35(7):1166-1173

20. Alfonso JF, Fernandez-Vega L, Lisa C, Fernandes P, GonzálezMéijome JM, Montés-Micó R. Collagen copolymer toric posterior chamber phakic intraocular lens in eyes with keratoconus. J Cataract Refract Surg. 2010;36(9):906-916.

21. Mertens EL, Sanders DR, Vitale PN. Custom-designed toric phakic intraocular lenses to correct high corneal astigmatism. J Refract Surg. 2008;24(5):501-506.

22. Kamiya K, Shimizu K, Hikita F, Komatsu M. Posterior chamber toric phakic intraocular lens implantation for high myopic astigmatism in eyes with pellucid marginal degeneration. J Cataract Refract Surg. 2010;36(1):164-166.

23. Chen LJ, Chang YJ, Kuo JC, Rajagopal R, Azar DT. Metaanalysis of cataract development after phakic intraocular lens surgery. J Cataract Refract Surg. 2008;34(7):1181-1200.

24. Gonvers M, Othenin-Girard P, Bornet C, Sickenberg M. Implantable contact lens for moderate to high myopia: short-term fol- 
low-up of 2 models. J Cataract Refract Surg. 2001;27(3):380-388.

25. Sanchez-Galeana CA, Smith RJ, Sanders DR, et al. Lens opacities after posterior chamber phakic intraocular lens implantation. Ophthalmology. 2003;110(4):781-785.

26. Lackner B, Pieh S, Schmidinger G, et al. Long-term results of implantation of phakic posterior chamber intraocular lenses. J Cataract Refract Surg. 2004;30(11):2269-2276.

27. Sarikkola AU, Sen HN, Uusitalo RJ, Laatikainen L. Traumatic cataract and other adverse events with the implantable contact lens. J Cataract Refract Surg. 2005;31(3):511-524.

28. Bleckmann H, Keuch RJ. Results of cataract extraction after implantable contact lens removal. J Cataract Refract Surg. 2005;31(12):2329-2333.

29. Chang JS, Meau AY. Visian Collamer phakic intraocular lens in high myopic Asian eyes. J Refract Surg. 2007;23(1):17-25.

30. Sanders DR. Anterior subcapsular opacities and cataracts 5 years after surgery in the visian implantable collamer lens FDA trial. J Refract Surg. 2008;24(6):566-570.

31. Alfonso JF, Lisa C, Abdelhamid A, Fernandes P, Jorge J, Montés-Micó R. Three-year follow-up of subjective vault following myopic implantable collamer lens implantation. Graefes Arch Clin Exp Ophthalmol. 2010;248(12):1827-1835.

32. Chung TY, Park SC, Lee MO, Ahn K, Chung ES. Changes in iridocorneal angle structure and trabecular pigmentation with STAAR implantable collamer lens during 2 years. J Refract Surg. 2009;25(3):251-258.

33. Kamiya K, Shimizu K, Igarashi A, Hikita F, Komatsu M. Fouryear follow-up of posterior chamber phakic intraocular lens implantation for moderate to high myopia. Arch Ophthalmol. 2009;127(7):845-850.

34. Boxer Wachler BS, Scruggs RT, Yuen LH, Jalali S. Comparison of the Visian ICL and Verisyse phakic intraocular lenses for myopia from 6.00 to 20.00 diopters. J Refract Surg. 2009;25(9):765-770.

35. Schmidinger G, Lackner B, Pieh S, Skorpik C. Long-term changes in posterior chamber phakic intraocular collamer lens vaulting in myopic patients. Ophthalmology. 2010;117(8):1506-1511.

36. Rayner SA, Bhikoo R, Gray T. Spherical implantable collamer lenses for myopia and hyperopia: 126 eyes with 1-year follow up. Clin Experiment Ophthalmol. 2010;38(1):21-26.

37. Kamiya K, Shimizu K, Aizawa D, Igarashi A, Komatsu M, Nakamura A. One-year follow-up of posterior chamber toric phakic intraocular lens implantation for moderate to high myopic astigmatism. Ophthalmology. 2010;117(12):2287-2294.

38. Sanders DR, Vukich JA; ICL in Treatment of Myopia (ITM) Study Group. Incidence of lens opacities and clinically significant cataracts with the implantable contact lens: comparison of two lens designs. J Refract Surg. 2002;18(6):673-682.

39. Gonvers M, Bornet C, Othenin-Girard P. Implantable contact lens for moderate to high myopia: relationship of vaulting to cataract formation. J Cataract Refract Surg. 2003;29(5):918-924.

40. Shiratani T, Shimizu K, Fujisawa K, Uga S, Nagano K, Murakami Y. Crystalline lens changes in porcine eyes with implanted phakic IOL (ICL) with a central hole. Graefes Arch Clin Exp Ophthalmol. 2008;246(5):719-728.

41. Fujisawa K, Shimizu K, Uga S, et al. Changes in the crystalline lens resulting from insertion of a phakic IOL (ICL) into the porcine eye. Graefes Arch Clin Exp Ophthalmol. 2007;245(1):114-122.

42. Khalifa YM, Moshirfar M, Mifflin MD, Kamae K, Mamalis N, Werner L. Cataract development associated with collagen copolymer posterior chamber phakic intraocular lenses: clinicopathological correlation. J Cataract Refract Surg. 2010;36(10):1768-1774.

43. Moshirfar M, Mifflin M, Wong G, Chang JC. Cataract surgery following phakic intraocular lens implantation. Curr Opin Oph- thalmol. 2010;21(1):39-44.

44. Espandar L, Meyer JJ, Moshirfar M. Phakic intraocular lenses. Curr Opin Ophthalmol. 2008;19(4):349-356.

45. Kamiya K, Shimizu K, Igarashi A, Aizawa D, Ikeda T. Clinical outcomes and patient satisfaction after Visian Implantable Collamer Lens removal and phacoemulsification with intraocular lens implantation in eyes with induced cataract. Eye (Lond). 2010;24(2):304-309.

46. Morales AJ, Zadok D, Tardio E, et al. Outcome of simultaneous phakic implantable contact lens removal with cataract extraction and pseudophakic intraocular lens implantation. J Cataract Refract Surg. 2006;32(4):595-598.

47. Sanders DR, Bernitsky DA, Harton PJ Jr, Rivera RR. The Visian myopic implantable collamer lens does not significantly affect axial length measurement with the IOLMaster. J Refract Surg. 2008;24(9):957-959.

48. Chun YS, Park IK, Lee HI, Lee JH, Kim JC. Iris and trabecular meshwork pigment changes after posterior chamber phakic intraocular lens implantation. J Cataract Refract Surg. 2006;32(9):1452-1458.

49. Smallman DS, Probst L, Rafuse PE. Pupillary block glaucoma secondary to posterior chamber phakic intraocular lens implantation for high myopia. J Cataract Refract Surg. 2004;30(4):905-907.

50. Vetter JM, Tehrani M, Dick HB. Surgical management of acute angle-closure glaucoma after toric implantable contact lens implantation. J Cataract Refract Surg. 2006;32(6):1065-1067.

51. Bylsma SS, Zalta AH, Foley E, Osher RH. Phakic posterior chamber intraocular lens pupillary block. J Cataract Refract Surg. 2002;28(12):2222-2228.

52. Sanchez-Galeana CA, Zadok D, Montes M, Cortés MA, Chayet AS. Refractory intraocular pressure increase after phakic posterior chamber intraocular lens implantation. Am J Ophthalmol. 2002;134(1):121-123.

53. Park IK, Lee JM, Chun YS. Recurrent occlusion of laser iridotomy sites after posterior chamber phakic IOL implantation. Korean J Ophthalmol. 2008;22(2):130-132.

54. Shipper I. Surgical management of acute angle-closure glaucoma after implantation of a toric ICL. J Cataract Refract Surg. 2007;33(4):563-564.

55. Apel A, Stephensen D. Surgical management of acute angle-closure glaucoma after toric ICL implantation. J Cataract Refract Surg. 2007;33(10):1672.

56. Chan KC, Birchall W, Gray TB, Wells AP. Acute angle closure after implantable contact lens insertion unresponsive to surgical peripheral iridectomy. J Cataract Refract Surg. 2008;34(4):696-699.

57. Khalifa YM, Goldsmith J, Moshirfar M. Bilateral explantation of Visian Implantable Collamer lenses secondary to bilateral acute angle closure resulting from a non-pupillary block mechanism. J Refract Surg. 2010;26(12):991-994.

58. Abela-Formanek C, Kruger AJ, Dejaco-Ruhswurm I, Pieh S, Skorpik C. Gonioscopic changes after implantation of a posterior chamber lens in phakic myopic eyes. J Cataract Refract Surg. 2001;27(12):1919-1925.

59. Pineda-Fernández A, Jaramillo J, Vargas J, Jaramillo M, Jaramillo J, Galíndez A. Phakic posterior chamber intraocular lens for high myopia. J Cataract Refract Surg. 2004;30(11):2277-2283.

60. Dejaco-Ruhswurm I, Scholz U, Pieh S, et al. Long-term endothelial changes in phakic eyes with posterior chamber intraocular lenses. J Cataract Refract Surg. 2002;28(9):1589-1593.

61. Edelhauser HF, Sanders DR, Azar R, Lamielle H; ICL in Treatment of Myopia Study Group. Corneal endothelial assessment after ICL implantation. J Cataract Refract Surg. 2004;30(3):576-583.

62. Bourne WM, Nelson LR, Hodge DO. Central corneal endothelial 


\section{Potential Complications of ICL Implantation/Fernandes et al}

cell changes over a ten-year period. Invest Ophthalmol Vis Sci. 1997;38(3):779-782.

63. Allan BD, Argeles-Sabate I, Mamalis N. Endophthalmitis rates after implantation of the intraocular collamer lens: survey of users between 1998 and 2006. J Cataract Refract Surg. 2009;35(4):766-769.

64. Davis MJ, Epstein RJ, Dennis RF, Cohen JA. Culture-positive endophthalmitis after implantation of intraocular collamer lens. J Cataract Refract Surg. 2009;35(10):1826-1828.

65. Martinez-Castillo V, Boixadera A, Verdugo A, Elies D, Coret A, García-Arumi J. Rhegmatogenous retinal detachment in phakic eyes after posterior chamber phakic intraocular lens implantation for severe myopia. Ophthalmology. 2005;112(4):580-585.

66. Sanders DR, Vukich JA, Doney K, Gaston M; Implantable Contact Lens in Treatment of Myopia Study Group. U.S. Food and Drug Administration clinical trial of the Implantable Contact Lens for moderate to high myopia. Ophthalmology. 2003;110(2):255-266.

67. Yan PS, Lin HT, Wang QL, Zhang ZP. Anterior segment variations with age and accommodation demonstrated by slitlamp-adapted optical coherence tomography. Ophthalmology. 2010;117(12):2301-2307.

68. Reinstein DZ, Archer TJ, Silverman RH, Rondeau MJ, Coleman DJ. Correlation of anterior chamber angle and ciliary sulcus diameters with white-to-white corneal diameter in high myopes using artemis VHF digital ultrasound. J Refract Surg. 2009;25(2):185-194.

69. Kim KH, Shin HH, Kim HM, Song JS. Correlation between ciliary sulcus diameter measured by $35 \mathrm{MHz}$ ultrasound biomicroscopy and other ocular measurements. J Cataract Refract Surg. 2008;34(4):632-637.

70. Seo JH, Kim MK, Wee WR, Lee JH. Effects of white-to-white diameter and anterior chamber depth on implantable collamer lens vault and visual outcome. J Refract Surg. 2009;25(8):730-738.

71. Choi KH, Chung SE, Chung TY, Chung ES. Ultrasound biomicroscopy for determining visian implantable contact lens length in phakic IOL implantation. J Refract Surg. 2007;23(4):362-367.

72. Lege BA, Haigis W, Neuhann TF, Bauer MH. Age-related behavior of posterior chamber lenses in myopic phakic eyes during accommodation measured by anterior segment partial coherence interferometry. J Cataract Refract Surg. 2006;32(6):999-1006.

73. Petternel V, Koppl CM, Dejaco-Ruhswurm I, Findl O, Skorpik C, Drexler W. Effect of accommodation and pupil size on the movement of a posterior chamber lens in the phakic eye. Ophthalmology. 2004;111(2):325-331.

74. Alfonso JF, Ferrer-Blasco T, González-Méijome JM, et al. Pupil size, white-to-white corneal diameter, and anterior chamber depth in patients with myopia. J Refract Surg. 2010;26(11):891-898.

75. Atchison DA, Markwell EL, Kasthurirangan S, Pope JM, Smith G, Swann PG. Age-related changes in optical and biometric characteristics of emmetropic eyes. J Vis. 2008;8(4):29.1-20.

76. Kojima T, Maeda M, Yoshida Y, et al. Posterior chamber phakic implantable collamer lens: changes in vault during 1 year. J Refract Surg. 2010;26(5):327-332.

77. Kamiya K, Shimizu K, Kawamorita T. Changes in vaulting and the effect on refraction after phakic posterior chamber intraocular lens implantation. J Cataract Refract Surg. 2009;35(9):15821586.

78. Strenk SA, Strenk LM, Guo S. Magnetic resonance imaging of the anteroposterior position and thickness of the aging, accommodating, phakic, and pseudophakic ciliary muscle. J Cataract Refract Surg. 2010;36(2):235-241. 